\title{
Total alkaloids of Corydalis saxicola bunting inhibits migration of A549 cells by suppressing Cdc42 or Vav1
}

\author{
MIMI LI ${ }^{1}$, JIYING WANG ${ }^{2}$, BIWEN MO $^{2}$, JINRONG ZENG $^{2}$, DONG YAO $^{2}$, \\ FENG CHEN $^{2}$, MING JIANG $^{2}$, LIZONG RAO ${ }^{1}$ and YINJUN DU ${ }^{1}$ \\ ${ }^{1}$ Institute of Respiratory Diseases, Guilin Medical University; ${ }^{2}$ Department of Respiratory, \\ The Affiliated Hospital of Guilin Medical University, Guilin, Guangxi 541000, P.R. China
}

Received June 8, 2016; Accepted September 15, 2017

DOI: $10.3892 / \mathrm{ol} .2017 .7273$

\begin{abstract}
Cell division cycle 42 (Cdc42) is a critical regulator, which functions in cancer metastasis. Numerous previous studies have demonstrated that vav guanine nucleotide exchange factor 1 (Vav1) is ectopically expressed in numerous types of human malignancies and have suggested that Vav1 may efficiently promote the formation of invadopodia and matrix degradation by regulating the activation of Cdc42. Total alkaloids of Corydalis saxicola bunting (TAOCSB), a type of alkaloid compound extracted from the root of $C$. saxicola bunting, has been revealed to have anticancer properties. However, there is no available information to address the effects of TAOCSB on the metastasis of human lung cancer. In the present study, the anticancer effect on A549 non-small cell lung cancer cells induced by TAOCSB was investigated, as well as its underlying mechanisms. The results demonstrated that a low dose of TAOCSB exhibited anti-metastatic potential in suppressing the invasion and migration of A549 cells, and this action may be involved in TAOCSB-mediated inhibition of $\mathrm{Cdc} 42$ expression at the level of mRNA and protein in parallel with TAOCSB-mediated inhibition of matrix metalloproteinase (MMP)-2 and MMP-9 protein expression levels. Although the present study did not reveal the expression level of Vav1 protein in A549 cells, the expression level of Vav1 mRNA was investigated. The effect of Vav1 expression in A549 cells requires further study. Overall, the results of the present study revealed that TAOCSB may provide more information regarding lung cancer treatment.
\end{abstract}

Correspondence to: Professor Jiying Wang, Department of Respiratory, The Affiliated Hospital of Guilin Medical University, 15 Le Qun Road, Guilin, Guangxi 541000, P.R. China

E-mail: 429400237@qq.com

Key words: total alkaloids of Corydalis saxicola bunting, A549 cells, invasion, migration, cell division cycle 42, vav guanine nucleotide exchange factor 1

\section{Introduction}

To date, lung cancer has the highest cancer-related mortality rates in females and male worldwide (1), and non-small cell lung cancer (NSCLC) accounts for between 80 and $85 \%$ of all cases of lung cancer (2). While a number of chemotherapeutic agents mediate their effects by inducing the apoptosis of cancer cells, metastasis remains a main factor contributing to patient mortality. Previous studies have suggested that metastasis may occur earlier than the formation of a primary tumor $(3,4)$. Many patients with NSCLC at the time of initial diagnosis have aggressive and early metastasis, thus the 5 -year survival rate of NSCLC is as low as $11 \%$ (5). Therefore, inhibiting the invasion and migration of lung cancer should be considered as an efficient therapeutic method for treating lung cancer, particularly prior to detectable metastatic disease.

Metastasis is a multiple-steps process (6). Previous studies investigating its underlying molecular mechanisms may provide specific drug targets for controlling the spread of cancer. Vav guanine nucleotide exchange factor 1 (Vav1), is a guanine nucleotide exchange factor (GEF), serves a pivotal role in hematopoietic cells and has been revealed to be ectopically expressed in numerous types of cancer, including neuroblastoma (7), ovarian cancer (8), breast cancer (9), pancreatic ductal adenocarcinoma (PDA) (10), melanoma (11) and lung cancer (12). Conversely, Cell division cycle 42 (Cdc42), which is regularly activated by GEFs, is a family member of small RhoGTPases and has also been revealed to serve a role in cancer (13-16). In PDA, Vav1 GEF activity may efficiently promote the formation of invadopodia and matrix degradation by regulating the activation of $\mathrm{Cdc} 42$ (17). Also, it has been reported that $\mathrm{Cdc} 42$ is overexpressed in lung adenocarcinoma (18), and that the knockdown of $\mathrm{Cdc} 42$ was associated with suppression of gastric cancer cell migration (19). The present study investigated whether Vav1 or Cdc 42 may be an ideal drug target for the treatment of lung cancer metastasis.

In the clinic, platinum-based drugs are the main first-line treatment for lung cancer metastasis (20). However, toxicity and side effects, including gastrointestinal and myeloid disorders, are inevitable. Therefore, novel improved drugs targeting specific cancer metastatic factors are urgently required. Of note, traditional Chinese herbal medicines have received increasing interest worldwide as anticancer agents (21). There 
are studies suggesting that agents derived from natural plant species possess the ability to inhibit cancer cell survival independently (22). Certain natural agents are able to enhance the anticancer effect of first-line drugs $(23,24)$.

Total alkaloids of Corydalis saxicola bunting (TAOCSB) is a traditional Chinese herbal medicine and possesses numerous biological activities, including anti-inflammatory, antimicrobial, anticancer, immune-regulatory and central nervous sedative effects (25-27). Previous studies have suggested that TAOCSB has been used as an effective auxiliary curable method for hepatoma (28). TAOCSB acquires the ability to inhibit proliferation and induce apoptosis in a number of cancer cell lines, including tongue squamous carcinoma, liver cancer and ovarian cancer cells (29-31). The present study demonstrated that TAOCSB facilitated apoptosis and reversed the process of epithelial to mesenchymal transition (EMT) in A549 lung cancer cells. In conclusion, TAOCSB is hypothesized to suppress the metastasis of A549 cells. Further confirmatory studies should investigate whether TAOCSB exerts its functions as suggested in the present study and the possible underlying mechanisms involved.

\section{Materials and methods}

Cell culture. A549 human NSCLC cells were purchased from Kunming Cell Bank of the Chinese Academy of Sciences (Shanghai, China) and were cultured in Dulbecco's modified Eagle's medium (DMEM; Gibco; Thermo Fisher Scientific, Inc., Waltham, MA, USA) supplemented with $10 \%$ (v/v) fetal bovine serum (FBS; Gemini Bio Products, West Sacramento, CA, USA) and $1 \%(\mathrm{v} / \mathrm{v})$ penicillin/streptomycin (Invitrogen; Thermo Fisher Scientific, Inc.) in a 5\% $\mathrm{CO}_{2}$ humid atmosphere and saturated humidity at $37^{\circ} \mathrm{C}$. Cells in the logarithmic growth phase were used for subsequent experiments.

Reagents. MTT was purchased from Sigma-Aldrich (Merck KGaA, Darmstadt, Germany). Rabbit anti-human Cdc42 monoclonal antibody (ab187643) and mouse anti-human Vav1 monoclonal antibody (ab187643) were obtained from Abcam (Cambridge, UK). Rabbit anti-human matrix metalloproteinase (MMP)-9 monoclonal antibody (WL01580) and rabbit anti-human MMP-2 monoclonal antibody (WL1579) supplied by Wanleibo Co., Ltd. (Shanghai, China). ML141 (Cdc42 inhibitor; S7686) was purchased from Selleck Chemicals (Houston, TX, USA). Transwell chambers were obtained from Corning Incorporated (NY, USA). All the primer sequences used for reverse transcription-quantitative polymerase chain reaction (RT-qPCR) were purchased from Generay Biotech Co, Ltd. (Shanghai, China).

Cell viability assay. For all studies, A549 cells were incubated at $37^{\circ} \mathrm{C}$ with $5 \% \mathrm{CO}_{2}$ in a humidified atmosphere. TAOCSB was dissolved in dimethylsulfoxide (DMSO), with DMSO-treatment serving as a control. In this assay, cells were seeded into 96-well plates at a density of $\sim 2.5 \times 10^{4}$ cells $/ \mathrm{ml}$ overnight. Subsequently, each group of wells was treated with $0-40 \mu \mathrm{g} / \mathrm{ml}$ TAOCSB at $37^{\circ} \mathrm{C}$. After $24 \mathrm{~h}, 5.0 \mathrm{mg} / \mathrm{ml}$ MTT was added to each well. After a further incubation for $4 \mathrm{~h}$ at $37^{\circ} \mathrm{C}, 150 \mu \mathrm{l}$ DMSO was loaded into each well and agitated to dissolve the crystals in the viable cells. The optical density
(OD) value was read at $490 \mathrm{~nm}$ using an automated microplate reader. The results are presented as the mean of all readings. Cell viability rate $=\mathrm{OD}$ of experimental group $/ \mathrm{OD}$ of control group $\times 100 \%$. A total of 7 sets of experiments were performed, each containing 6 wells per treatment. All experiments were performed in triplicate.

Wound healing assay. A549 cells $\left(15 \times 10^{4}\right.$ per well) were plated in 6-well plates. Once the cells in the individual wells had achieved $80-90 \%$ confluence after $\sim 16 \mathrm{~h}$, a wound was created by gently scratching the surface using a sterile pipette tip. Subsequently, the cells were treated with various doses of TAOCSB $(0,5,7.5$ or $10 \mu \mathrm{g} / \mathrm{ml})$ at $37^{\circ} \mathrm{C}$ for $24 \mathrm{~h}$. Cells were imaged at 0 and $24 \mathrm{~h}$ using a phase-contrast microscope (magnification, $x 100$ ). The motility ratio of cells was evaluated by measuring the width of the wound at an identical position. All experiments were performed in triplicate.

Migration and invasion assays. Using Matrigel-coated chamber invasion plates, A549 cells $\left(2 \times 10^{4}\right.$ cells per well) were added to the upper chamber in serum-free medium containing various doses of TAOCSB $(0,5,7.5$ or $10 \mu \mathrm{g} / \mathrm{ml})$ and the lower chamber containing DMEM supplemented with $10 \%$ FBS and TAOCSB $(0,5,7.5$ or $10 \mu \mathrm{g} / \mathrm{ml})$. The plates were incubated at $37^{\circ} \mathrm{C}$ for $24 \mathrm{~h}$. The cells that invaded through the Matrigel were fixed with pre-cooled methanol (100\%), washed with PBS at $37^{\circ} \mathrm{C}$ and stained with $0.1 \%$ crystal violet for $30 \mathrm{~min}$ at room temperature. The cells were subsequently counted under a light microscope at a magnification of x200. All experiments were performed in triplicate.

Western blot analysis. A549 cells were seeded into $10 \mathrm{~cm}^{2}$ culture dishes, when cells were grown to a confluence of $70-80 \%$. The total protein in each group was collected after $24 \mathrm{~h}$ using radioimmunoprecipitation assay lysis buffer (P0013K; Beyotime Institute of Biotechnology, Haimen, China) on ice. Protein concentration was determined using the bicinchoninic acid protein assay kit (orb219872; Biorbyt Ltd., Cambridge, UK), according to the manufacturer's protocol. For each sample, $30 \mu \mathrm{g}$ protein was separated by SDS-PAGE (10\% gel) and transferred onto a polyvinylidene fluoride membrane. The membrane was blocked in Blocking buffer (Beyotime Institute of Biotechnology) at room temperature for $1 \mathrm{~h}$, then incubated with Cdc42 (1:1,000), MMP-2 (1:1,000), MMP-9 $(1: 2,000)$ and $\beta$-actin (1:2,000; Origene Technologies, Inc., Beijing, China; cat. no. TA-09) primary antibodies at $4^{\circ} \mathrm{C}$ overnight. Following washing with Tris-buffered saline and Tris-buffered saline containing Tween-20 buffers, antibody binding was detected using horseradish peroxidase-conjugated goat anti-mouse IgG secondary antibody (AP124P, dilution 1:5,000) and goat anti-rabbit IgG secondary antibody (A0545, dilution 1:5,000) at room temperature for $1 \mathrm{~h}$. The binding bands were visualized using enhanced chemiluminescence (orb90504; Biorbyt Ltd.) and autoradiography. Protein bands were analyzed using Quantity One 1-D analysis software (Version 4.6.2, Bio-Rad Laboratories, Inc., Hercules, CA, USA) and normalized to the $\beta$-actin signal.

$R T$ - $q P C R$ analysis. Total mRNA was isolated from A549 cells in the exponential growth phase using TRIzol ${ }^{\circledR}$ reagent 
(Invitrogen; Thermo Fisher Scientific, Inc.), according to the manufacturer's protocol. RNA (1 $\mu \mathrm{g}$ per reaction) was reverse-transcribed to yield first-strand cDNA using transcriptase (DBI Bioscience, Shanghai, China). Diluted cDNA was then mixed with pairs of specific primers and SYBR Green PCR Master Mix (DBI Bioscience) in a total volume of $15 \mu 1$. The PCR cycling conditions were as follows: 2 min at $95^{\circ} \mathrm{C}$ for $1 \mathrm{cycle}, 10 \mathrm{sec}$ at $95^{\circ} \mathrm{C}, 34 \mathrm{sec}$ at $55^{\circ} \mathrm{C}$ and $30 \mathrm{sec}$ at $72^{\circ} \mathrm{C}$ for 40 cycles. Relative mRNA levels were calculated based on $\mathrm{Cq}$ values and corrected for the $18 \mathrm{~S}$ expression according to the equation $2^{-\triangle \Delta C q}(32)$. The sequences of the primers were as follows: Cdc42 sense, 5'-TTTCTTGCTTGTTGGGACT-3' and antisense, 5'-GGCTTCTGTTTGTTCTTGG-3'; Vav1 sense, 5'-AAGCGAGACAACGAGACA-3' and antisense, 5'-GCCATAGTGAGCCAGAGA-3'; $\beta$-actin sense, 5'-GAC ATCCGCAAAGACCTG-3' and antisense, 5'-GGAAGGTGG ACAGCGAG-3'. The analysis was performed using the ABI Prism 7500 Real-Time PCR technology (Applied Biosystems; Thermo Fisher Scientific, Inc.). Each cDNA sample was run three times independently. The quantification of the expression of the detectable gene was normalized to that of $\beta$-actin in corresponding samples.

Statistical analysis. SPSS (version 18.0; SPSS, Inc., Chicago, IL, USA) for Windows was used for all analyses. All quantitative data are presented as the mean value \pm standard deviation of three independent experiments. The differences between the groups were analyzed by one-way analysis of variance followed by Tukey's post hoc test. $\mathrm{P}<0.05$ or $\mathrm{P}<0.01$ were considered to indicate statistically significant differences.

\section{Results}

Effects of various concentrations of TAOCSB on the viability of A549 cells. Treatment of A549 cells with various concentration of TAOCSB for $24 \mathrm{~h}$ resulted in dose-dependent growth inhibition (Fig. 1). For treatment with $10 \mu \mathrm{g} / \mathrm{ml}$ TAOCSB, the relative cell survival rate of A549 cells was $~ 40 \%$. Therefore, using a concentration below $10 \mu \mathrm{g} / \mathrm{ml}$ may inhibit cell migration or invasion in a pathological state.

TAOCSB inhibits the migration and invasion of A549 cells in vitro. Increased cell motility and invasion of carcinoma cells are key steps in the process of metastasis. The present study subsequently examined the effect of TAOCSB on the ability of A549 cells to migrate and invade by wound healing and Transwell assays, respectively. Wound healing experiment results revealed that TAOCSB-treated A549 cells exhibited lower mobility rates compared with the control in a dose-dependent manner (Fig. 2A and B). Consistent with these results, the number of TAOCSB-treated A549 cells that invaded was also significantly lower compared with the control (Fig. 3A), and the quantification of cells in the lower chamber demonstrated statistical significance (Fig. 3B). These results demonstrated the inhibitory effect of TAOCSB on the rates of migration and invasion in A549 lung cancer cells.

TAOCSB inhibits Cdc42 expression in A549 cells. For Cdc42, promoting the formation of invadopodia structures contributes to enhanced metastasis. The present study therefore

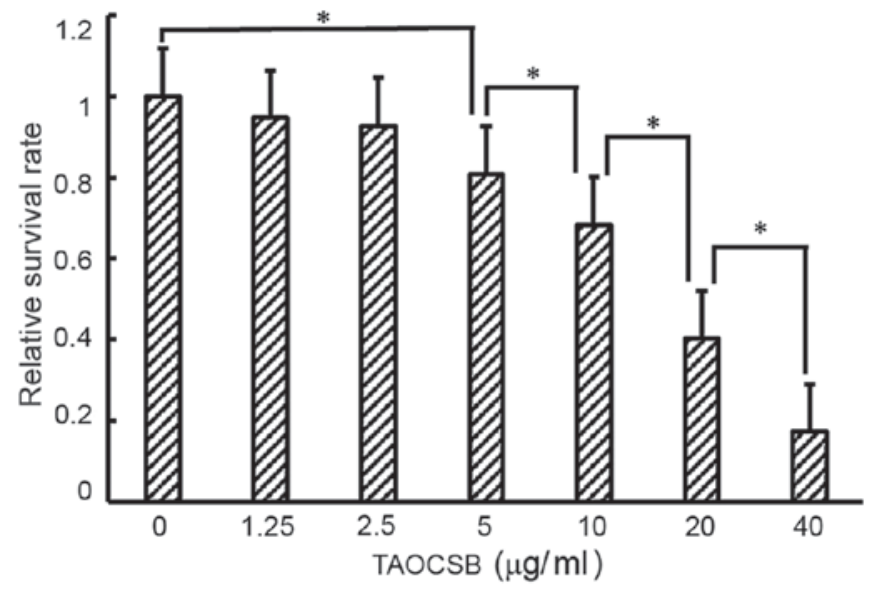

Figure 1. Inhibitory effect of TAOCSB on the growth of A549 cells. ${ }^{*} \mathrm{P}<0.01$. TAOCSB, total alkaloids of Corydalis saxicola bunting.

investigated whether the effects reported in A549 cells were associated with variations in the level of $\mathrm{Cdc} 42$ expression by performing RT-qPCR at the mRNA level and western blot analysis at the protein level. In untreated cells, the expression levels of Cdc42 protein and mRNA were high (Fig. 4). The mRNA and protein expression level of Cdc 42 was investigated following the treatment with $5-10 \mu \mathrm{g} / \mathrm{ml}$ TAOCSB. These results revealed a decrease in the expression of $\mathrm{Cdc} 42$ at the protein and mRNA levels in a dose-dependent manner.

TAOCSB inhibits the expression levels of MMP-9 and MMP-2 in $A 549$ cells. Cdc42 is involved in the activation of MMPs responsible for extracellular matrix digestion, which is required for tumor cell invasion. Therefore, the present study evaluated whether TAOCSB-mediated decrease in Cdc42 protein expression level in A549 cells was paralleled by variations in the levels of MMP-2 and MMP-9 protein expression. The results revealed that treatment with TAOCSB was able to markedly inhibit the protein expression levels of MMP-2 and MMP-9 in A549 cells (Fig. 5). Furthermore, the decrease in MMP-2 and MMP-9 expression levels mediated by TAOCSB was dose-dependent.

Variant analysis of the levels of MMP-9 and MMP-2 protein expression following cdc42 inhibitor (ML141) treatment. Although it has been demonstrated that TAOCSB may decrease the expression levels of Cdc42, MMP-2 and MMP-9, whether TAOCSB is able to selectively inhibit the levels of total cdc 42 protein, which leads to defective secretion of MMP-9 and MMP-2 in A549 cells, required further investigation.

For further experiments, a new specific inhibitor of $\mathrm{Cdc} 42$ (ML141) was used. ML141 is a Cdc42 selective non-competitive inhibitor that prevents $\mathrm{Cdc} 42$ from bounding to guanosine triphosphate (GTP), which leads to inactive Cdc42 and reduction in the secretion of MMPs (33). As a result, there appeared to be no significant difference in MMP-9 and MMP-2 protein expression levels among ML141 and ML141 plus TAOCSB-treated groups (Fig. 6). Therefore, TAOCSB had no direct inhibitory effect on the expression levels of MMP-9 and MMP-2 proteins, the decrease of which may result from inhibition of active Cdc42-GTP by ML141. It was suggested that 
A

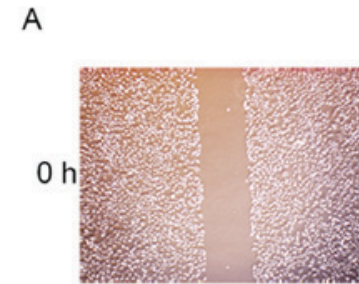

$0(\mu \mathrm{g} / \mathrm{ml})$

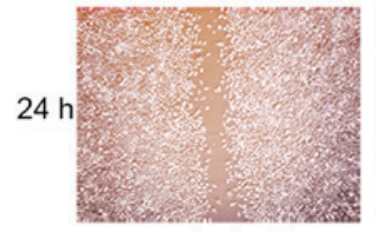

$0(\mu \mathrm{g} / \mathrm{ml})$

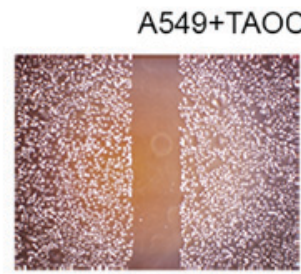

$5(\mu \mathrm{g} / \mathrm{ml})$

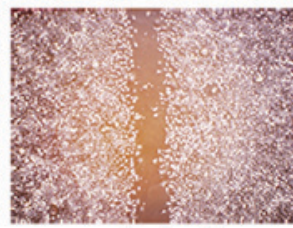

$5(\mu \mathrm{g} / \mathrm{ml})$

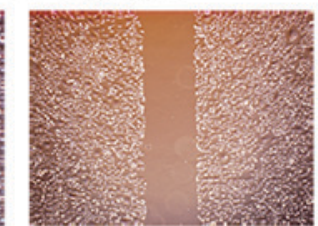

$7.5(\mu \mathrm{g} / \mathrm{ml})$

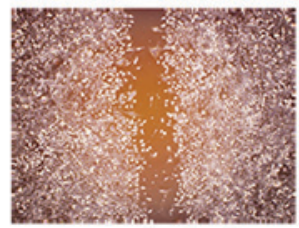

$7.5(\mu \mathrm{g} / \mathrm{ml})$

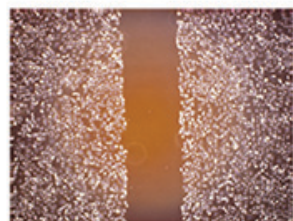

$10(\mu \mathrm{g} / \mathrm{ml})$

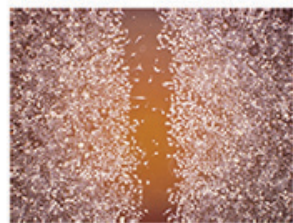

$10(\mu \mathrm{g} / \mathrm{ml})$

B

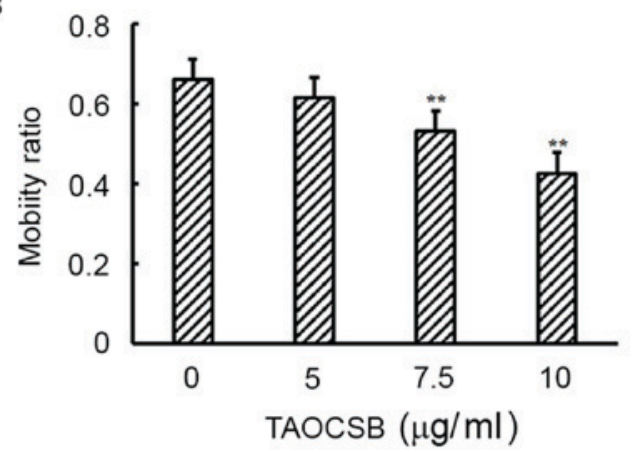

Figure 2. TAOCSB inhibits the migration of A549 cells in vitro as determined by wound healing assay. (A) A549 cells were imaged using phase-contrast microscope at $\mathrm{x} 100$ magnification. (B) Quantification of cell mobility. ${ }^{* *} \mathrm{P}<0.01$ vs. control. TAOCSB, total alkaloids of Corydalis saxicola bunting.

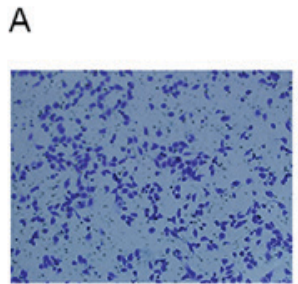

$0 \mu \mathrm{g} / \mathrm{ml}$

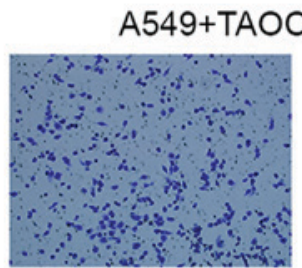

$5 \mu \mathrm{g} / \mathrm{ml}$

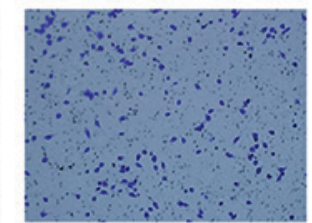

$7.5 \mu \mathrm{g} / \mathrm{ml}$

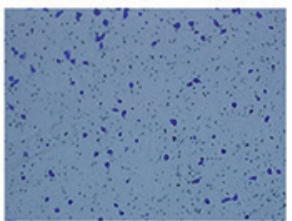

$10 \mu \mathrm{g} / \mathrm{ml}$

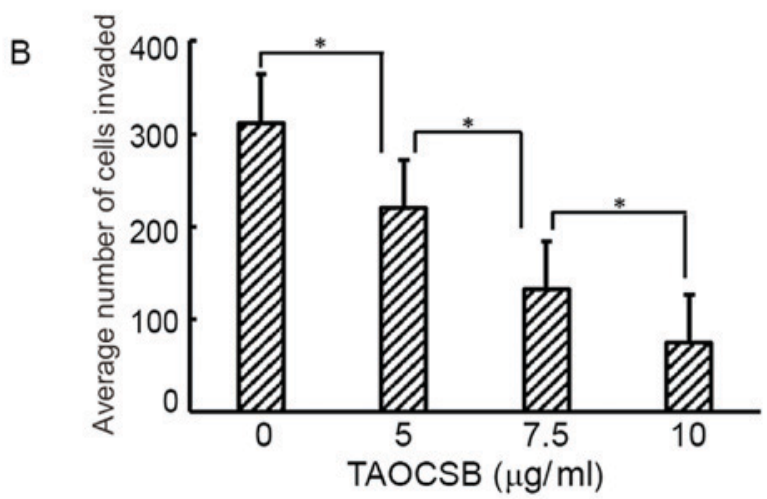

Figure 3. TAOCSB inhibits the invasion of A549 cells in vitro. The majority of A549 cells in the control group invaded from the upper chamber to the lower chamber. By contrast, the penetration of the Matrigel-coated chamber by A549 cells was inhibited by the presence of TAOCSB. (A) A549 cells in the lower chamber were imaged under a phase-contrast microscope at x400 magnification. (B) Quantification of cell invasion. Data are presented as the mean number of cells invaded. "P<0.01. TAOCSB, total alkaloids of Corydalis saxicola bunting.

Cdc 42 or factors upstream of Cdc 42 may be the drug target for TAOCSB in A549 cells, and TAOCSB-mediated inhibition of total Cdc42 may also limit the Cdc42-GTP bound state (Fig. 6). 
A
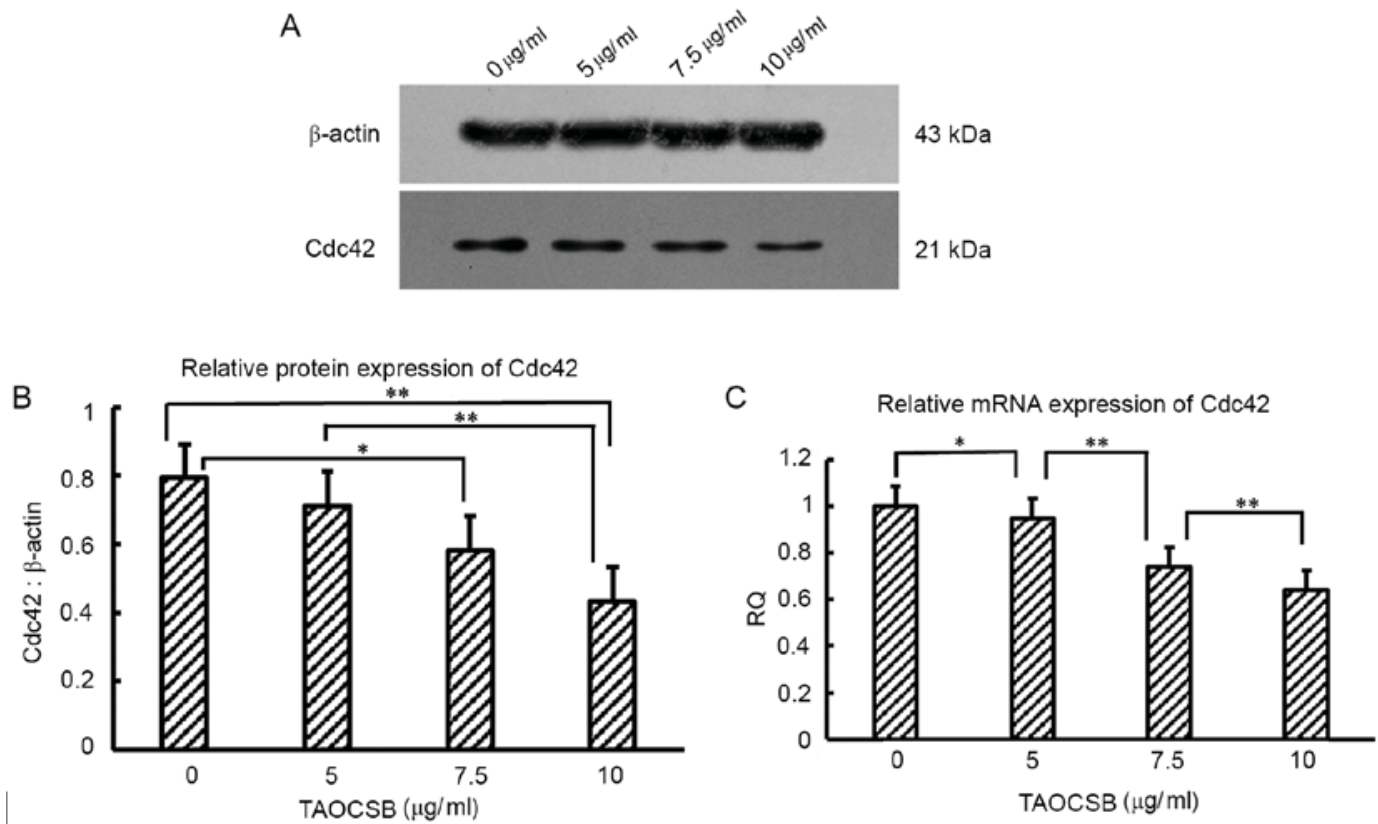

Figure 4. Effects of TAOCSB on Cdc $42 \mathrm{mRNA}$ and protein expression levels. A549 cells were treated with 5-10 $\mu \mathrm{g} / \mathrm{ml}$ TAOCSB for $24 \mathrm{~h}$. Results from reverse transcription-quantitative polymerase chain reaction and (A) western blotting revealed that TAOCSB inhibited Cdc42 (B) protein and (C) mRNA expression levels in a dose-dependent manner. " $\mathrm{P}<0.05$ or ${ }^{* *} \mathrm{P}<0.01$. RQ, relative quantification; TAOCSB, total alkaloids of Corydalis saxicola bunting; Cdc42, cell division cycle 42.

A

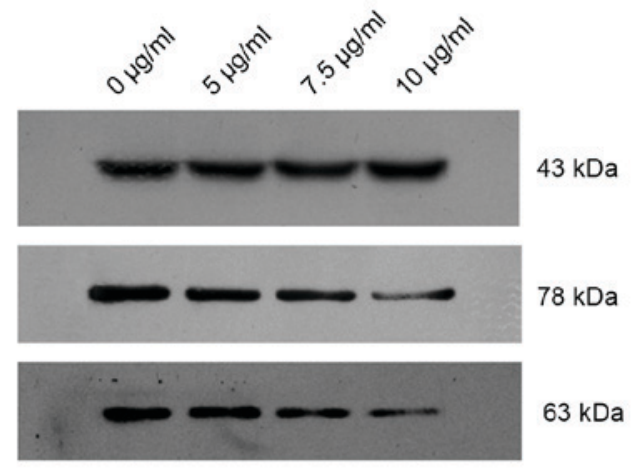

B

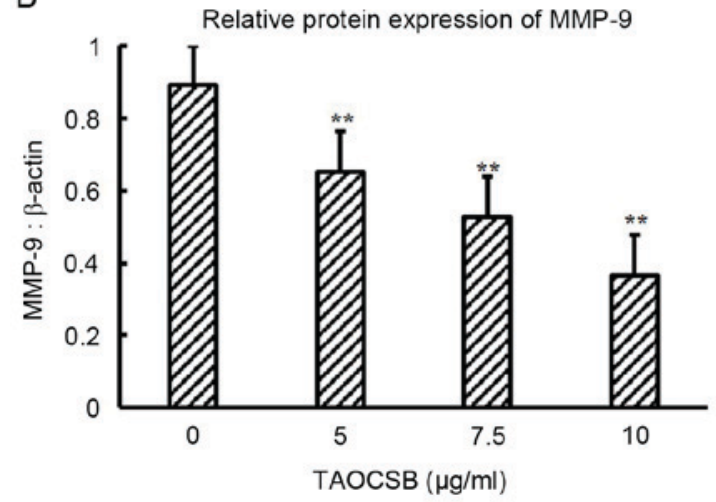

C

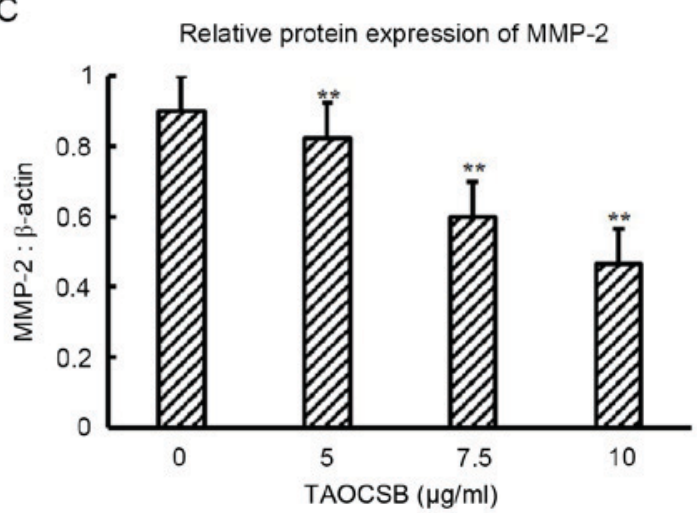

Figure 5. Effects of TAOCSB on MMP-9 and MMP-2 protein expression levels. A549 cells were treated with 5-10 $\mu \mathrm{g} / \mathrm{ml}$ TAOCSB for $24 \mathrm{~h}$. (A) Western blotting results. Statistical analysis revealed that the expression levels of (B) MMP-9 and (C) MMP-2 proteins in the control group were high, but following treatment with TAOCSB the expression of both proteins were markedly decreased. Treatment with TAOCSB was able to inhibit the expression of the two proteins in a dose-dependent manner. ${ }^{* *} \mathrm{P}<0.01$ vs. control. TAOCSB, total alkaloids of Corydalis saxicola bunting; MMP, matrix metalloproteinase.

Treatment with TAOCSB affects the level of Vavl expression in A549 cells. It was revealed that Vav1 may promote metastasis by activating Cdc 42 in PDA. Therefore, the present study suggested that the same association between Vav1 and 

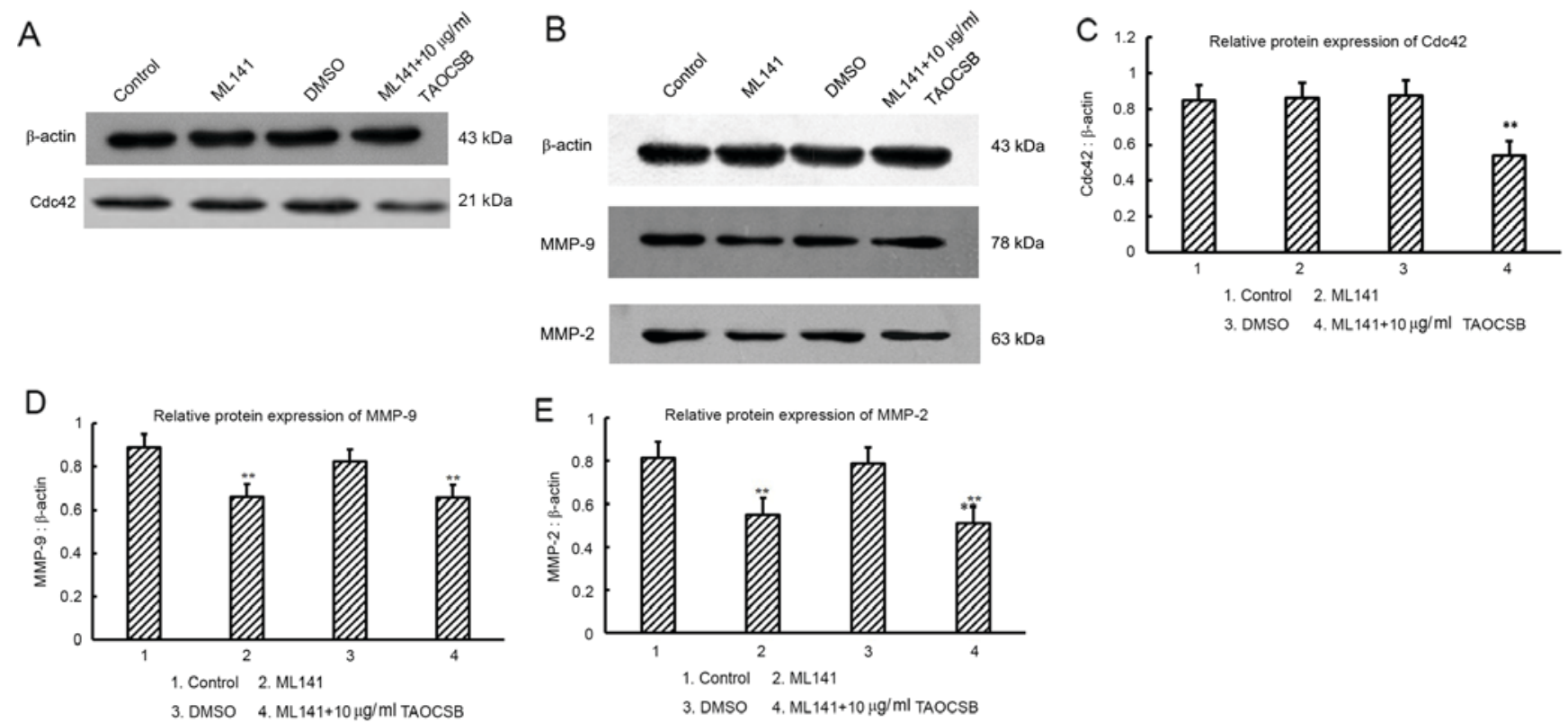

Figure 6. Effects of Cdc42 inhibitor (ML141) on the expression levels of MMP-9 and MMP-2 proteins. Western blots showing the effects of TAOCSB and ML141 treatment on the expression of (A) cdc42, (B) MMP-9 and MMP-2. (C) There was no statistical difference in cdc42 expression between the control, ML141-treated and DMSO-treated groups. ${ }^{* *} \mathrm{P}<0.01$ vs. ML141-treated group. Compared with the DMSO group, there were low levels of (D) MMP-9 and (E) MMP-2 expression in the ML141-treated group. There were no statistically significant differences in MMP-9 and MMP-2 expression between ML14-treated and ML141+TAOCSB-treated groups. ${ }^{*} \mathrm{P}<0.05$ or ${ }^{* *} \mathrm{P}<0.01$ vs. DMSO group. TAOCSB, total alkaloids of Corydalis saxicola bunting; MMP, matrix metalloproteinase; Cdc42, cell division cycle 42; DMSO, dimethylsulfoxide.

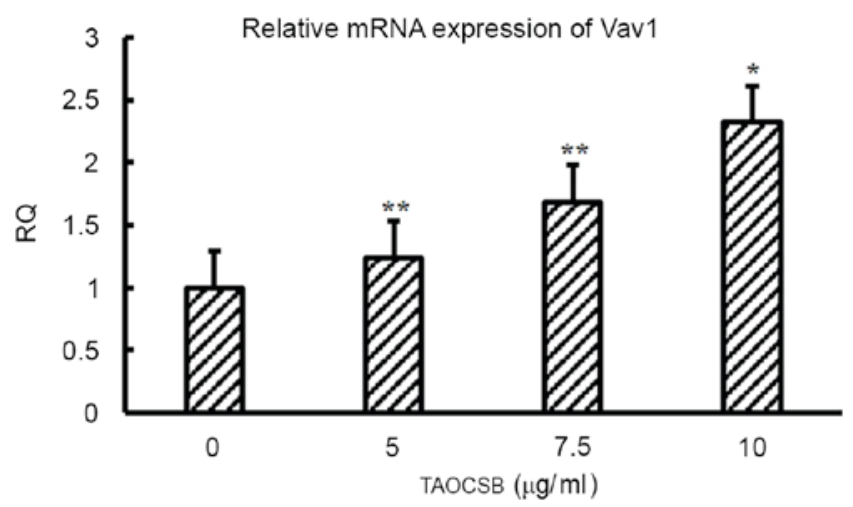

Figure 7. Effects of TAOCSB treatment on the level of Vav1 mRNA expression. Reverse transcription-quantitative polymerase chain reaction results indicated the presence of Vav1 mRNA expression in A549 cells and that TAOCSB had a dose-dependent effect on the expression of Vav1. "P<0.05 or ${ }^{* *} \mathrm{P}<0.01$ vs. control. TAOCSB, total alkaloids of Corydalis saxicola bunting, Vav1, vav guanine nucleotide exchange factor 1 ; RQ, relative quantification.

Cdc42 may exist in NSCLC. Of note, the mRNA expression level of Vav1 was identified, and treatment with TAOCSB may increase the level of Vav1 expression (Fig. 7).

\section{Discussion}

In a previous study, it was demonstrated that TAOCSB was able to inhibit the proliferation of A549 lung cancer cells, and this inhibitory effect was associated with cell cycle arrest at the $\mathrm{G}_{1} / \mathrm{S}$ phase, as well as induction of apoptosis via increasing the expression levels of caspase-3 and decreasing survivin expression (34). Subsequently, with suppression of the snail gene and increased E-cadherin protein expression,
TAOCSB may have reversed the effect of EMT. The present study aimed to investigate the effects of TAOCSB on the metastasis of NSCLC A549 cells and the associated underlying mechanisms.

Cdc42 is overexpressed in various types of cancer $(35,36)$. In lung cancer, Cdc42 is overexpressed in lung adenocarcinoma (18). A recent study demonstrated that the knockdown of Cdc42 may markedly suppress the migration and invasion of gastric cancer cells (19). Another previous study revealed that the overexpression of Cdc42 in lung cancer cell line 801D was downregulated by curcumin (24). Additionally, Vav1 as a GEF serves a pivotal role in the development of cancer, which is particularly associated with cancer metastasis (17). In PDA, Cdc42 was revealed to be a main downstream factor for Vav1, rather than other RAS superfamily members. However, targeting Vav1 may efficiently suppress the formation of invadopodia and matrix degradation (37).

Degradation of the basement membrane and extracellular matrix is an essential step for cancer cells to escape from the primary tumor site. MMP-9 and MMP-2, as a class of zinc-dependent enzymes, serve a pivotal role in this process $(38,39)$. Conversely, restricted expression levels of MMP-2 and MMP-9 in cancer cells leads to an improved prognosis (40-42). According to a number of studies, Cdc42 is involved in the formation and stabilization of invadopodia structures in cancer cells $(43,44)$. Additionally, Cdc42 may mediate the secretion of MMPs to enhance the function of invadopodia (45).

To the best of our knowledge, the present study revealed for the first time the inhibitory effect of TAOCSB on proliferation and migration of A549 lung cancer cells. By detecting variations of treatment conditions of the critical factor, $\mathrm{Cdc} 42$, in TAOCSB-treated A549 cells, the present study demonstrated 
that a low dose of TAOCSB was sufficient to reduce the expression level of Cdc42 at the level of mRNA and protein. In addition, the protein expression levels of MMP-2 and MMP-9 were also attenuated following decreased Cdc42 expression. To verify whether TAOCSB directly reduced MMP expression, the present study used the inhibitor of Cdc42 (ML141) in further experiments. It was revealed that TAOCSB did not directly inhibit the expression levels of MMP-9 and MMP-2 proteins. It remains unclear whether TAOCSB targets Cdc42 or its upstream factors directly to mediate the observed decrease in MMP-9 and MMP-2 expression levels and the reduced invasiveness of A549 cells. The present study did not investigate the protein expression level of Vav1 in A549 cells. However, it was hypothesized that Vav1 expression may be deregulated rapidly by calcineurin B-like proteins in A549 cells, which is similar to the effect observed in AU565 breast cancer cells (46). The present study determined Vav1 expression at the mRNA level. Although Vav1 is usually associated with matrix degradation and the formation of invadopodia, the anticancer effect of Vav1 remains uncertain; however, in the present study, it was identified that TAOCSB had a promoting effect on Vav1 mRNA expression. The activity of Vav may depend on additional genetic aberrations, including the p53 signaling pathway (46). Conversely, Grassilli et al (47) demonstrated high nuclear expression level of Vav1 in breast cancer tissues without lymphoma metastasis using the immunohistochemical technique. Compared with patients with high expression levels of Vav1, patients with low expression levels of Vav1 had a lower risk of distant metastasis. This observation may indicate that the risk of metastasis was associated with the distribution patterns of Vav1 protein in cancer cells.

In conclusion, it was identified that TAOCSB inhibited the proliferation and migration of A549 cells. It was also revealed that TAOCSB downregulated Cdc42 gene and protein expression, Cdc42 upstream factor Vav1, and downstream factors MMP2 and MMP9 expression in lung cancer cells. These results suggest that TAOCSB may inhibit tumor growth and invasion through the Cdc42 signal pathway. Further studies should be performed to uncover the role of Vav1 in cancer and to resolve the underlying molecular mechanisms in the pathogenesis of cancer.

\section{Acknowledgements}

The present study was supported by the National Natural Science Foundation of China (grant no. 81541172), Guangxi Health Department of Traditional Chinese Medicine (grant no. GZLC14-37), Traditional Chinese Medicine Science and Technology Projects of Guangxi Zhuang Autonomous Region Health Department (grant no. GZPT13-46).

\section{References}

1. Siegel RL, Miller KD and Jemal A: Cancer statistics, 2016. CA Cancer J Clin 66: 7-30, 2016.

2. Subramaniam S, Thakur RK, Yadav VK, Nanda R, Chowdhury S and Agrawal A: Lung cancer biomarkers: State of the art. J Carcinog 12: 3, 2013.

3. Rhim AD, Mirek ET, Aiello NM, Maitra A, Bailey JM, McAllister F, Reichert M, Beatty GL, Rustgi AK, Vonderheide RH, et al: EMT and dissemination precede pancreatic tumor formation. Cell 148: 349-361, 2012.
4. Haeno H, Gonen M, Davis MB, Herman JM, IacobuzioDonahue CA and Michor F: Computational modeling of pancreatic cancer reveals kinetics of metastasis suggesting optimum treatment strategies. Cell 148: 362-375, 2012.

5. Verdecchia A, Francisci S, Brenner H, Gatta G, Micheli A, Mangone L and Kunkler I; EUROCARE-4 Working Group: Recent cancer survival in Europe: A 2000-02 period analysis of EUROCARE-4 data. Lancet Oncol 8: 784-796, 2007.

6. Yilmaz M and Christofori G: Mechanisms of motility in metastasizing cells. Mol Cancer Res 8: 629-642, 2010.

7. Hornstein I, Pikarsky E, Groysman M, Amir G, Peylan-Ramu N and Katzav S: The haematopoietic specific signal transducer Vav1 is expressed in a subset of human neuroblastomas. J Pathol 199: 526-533, 2003

8. Wakahashi S, Sudo T, Oka N, Ueno S, Yamaguchi S, Fujiwara K, Ohbayashi C and Nishimura R: Vav1 represses E-cadherin expression through the transactivation of Snail and Slug: A potential mechanism for aberrant epithelial to mesenchymal transition in human epithelial ovarian cancer. Transl Res 162: 181-190, 2013.

9. Grassilli S, Brugnoli F, Lattanzio R, Rossi C, Perracchio L, Mottolese M, Marchisio M, Palomba M, Nika E, Natali PG, et al: High nuclear level of Vavl is positive prognostic factor in early invasive breast tumors: A role in modulating genes related to the efficiency of metastatic process. Oncotarget 5: 4320-4336, 2014.

10. Fernandez-Zapico ME, Gonzalez-Paz NC, Weiss E, Savoy DN, Molina JR, Fonseca R, Smyrk TC, Chari ST, Urrutia R and Billadeau DD: Ectopic expression of VAV1 reveals an unexpected role in pancreatic cancer tumorigenesis. Cancer Cell 7: 39-49, 2005.

11. Bartolomé RA, Molina-Ortiz I, Samaniego R, Sánchez-Mateos P, Bustelo XR and Teixidó J: Activation of Vav/Rho GTPase signaling by CXCL12 controls membrane-type matrix metalloproteinase-dependent melanoma cell invasion. Cancer Res 66: 248-258, 2006.

12. Lazer G, Idelchuk Y, Schapira V, Pikarsky E and Katzav S: The haematopoietic specific signal transducer Vav1 is aberrantly expressed in lung cancer and plays a role in tumourigenesis. J Pathol 219: 25-34, 2009

13. Liu Y, Wang Y, Zhang Y, Miao Y, Zhao Y, Zhang PX, Jiang GY, Zhang JY, Han Y, Lin XY, et al: Abnormal expression of p120-catenin, E-cadherin, and small GTPases is significantly associated with malignant phenotype of human lung cancer. Lung Cancer 63: 375-382, 2009.

14. Ye H, Zhang Y, Geng L and Li Z: Cdc42 expression in cervical cancer and its effect on cervical tumor invasion and migration. Int J Oncol 46: 757-763, 2015.

15. Kamai T, Yamanishi T, Shirataki H, Takagi K, Asami H, Ito Y and Yoshida K: Over-expression of RhoA, Rac1, and Cdc42 GTPases is associated with progression in testicular cancer. Clin Cancer Res 10: 4799-4805, 2004.

16. Kikuchi K, Li X, Zheng Y and Takano Y: Invasion of breast cancer cells into collage matrix requires TGF- $\alpha$ and $\mathrm{Cdc} 42$ signaling. FEBS Lett 585: 286-290, 2011.

17. Razidlo GL, Schroeder B, Chen J, Billadeau DD and McNiven MA: Vav1 as a central regulator of invadopodia assembly. Curr Biol 24: 86-93, 2014

18. Yao R, Wang Y, Lubet RA and You M: Differentially expressed genes associated with mouse lung tumor progression. Oncogene 21: 5814-5821, 2002.

19. Du DS, Yang XZ, Wang Q, Dai WJ, Kuai WX, Liu YL, Chu D and Tang XJ: Effects of CDC42 on the proliferation and invasion of gastric cancer cells. Mol Med Rep 13: 550-554, 2016.

20. Zarogoulidis K, Zarogoulidis P, Darwiche K, Boutsikou E, Machairiotis N, Tsakiridis K, Katsikogiannis N, Kougioumtzi I, Karapantzos I, Huang H and Spyratos D: Treatment of non-small cell lung cancer (NSCLC). J Thorac Dis 5 (Suppl 4): S389-S396, 2013.

21. Ma L, Wang B, Long Y and Li H: Effect of traditional Chinese medicine combined with Western therapy on primary hepatic carcinoma: A systematic review with meta-analysis. Front Med 11: 191-202, 2017.

22. Chen QY, Jiao DM, Yao QH, Yan J, Song J, Chen FY, Lu GH and Zhou JY: Expression analysis of Cdc42 in lung cancer and modulation of its expression by curcumin in lung cancer cell lines. Int J Oncol 40: 1561-1568, 2012.

23. Refaat A, Abdelhamed S, Yagita H, Inoue H, Yokoyama S, Hayakawa Y and Saiki I: Berberine enhances tumor necrosis factor-related apoptosis-inducing ligand-mediated apoptosis in breast cancer. Oncol Lett 6: 840-844, 2013. 
24. Ma L, Wang R, Nan Y, Li W, Wang Q and Jin F: Phloretin exhibits an anticancer effect and enhances the anticancer ability of cisplatin on non-small cell lung cancer cell lines by regulating expression of apoptotic pathways and matrix metalloproteinases. Int J Oncol 48: 843-853, 2016.

25. Li L: The effect of Corydalis saxicola Bunting on anti-inflammation. Chin J Ethnomed Ethnopharm 18: 20-21, 2009 (In Chinese).

26. Xie PS, Li AY, Zhou F and Zhao Y: The experimental screening of Chinese herbal medicine in anti-cancer effect. ShiZhen Chin Med: 19-20, 1996 (In Chinese).

27. Dong K, Wu LZ and Liang YY: The role of Corydalis saxicola alkaloids in mice immunity. Chin J Immunol: 238-241, 1995 (In Chinese).

28. Xiong LY and Li LL: The clinical trials of Octreotide combined Corydalis saxicola Bunting injection to treat advanced liver cancer. Sichuan Journal of Cancer Control: 232-234, 2005 (In Chinese).

29. Wu CF, Liu W, Li FL and Xu YM: The effect of Corydalis Saxicola bunting total alkaloids (CABTA) on monoamine neurotransmitters in rat brain. J Shenyang Pharm Univ: 101-104, 1994 (In Chinese).

30. Yin JK and Liao JX: The role of Corydalis Saxicola bunting total alkaloids on Tca8113 cells proliferation and apoptosis. Chin J of Oral and Maxillofacial Surg 4: 245-248, 2010 (In Chinese).

31. Tang CL, Zheng H, Wang J, Song H, Lu SY, Cheng B, Wu F, Zhang HY, Ruan JX, Liang YH and Su ZH: The active component identification of herba Corydalis saxicolae extract base on the quantitative composition-activity relationship in inhibition of human liver cancer cells SMMC-7721. ShiZhen Chin Med 27: 2372-2375, 2016 (In Chinese).

32. Livak KJ and Schmittgen TD: Analysis of relative gene expression data using real-time quantitative PCR and the 2(-Delta Delta C(T)) method. Methods 25: 402-408, 2001.

33. Hong L, Kenney SR, Phillips GK, Simpson D, Schroeder CE, Nöth J, Romero E, Swanson S, Waller A, Strouse JJ, et al: Characterization of a $\mathrm{Cdc} 42$ protein inhibitor and its use as a molecular probe. J Biol Chem 288: 8531-8543, 2013.

34. Jin Hua LI, Ji Ying Wang and Jing Rong Zeng: Total alkaloids of Corydalis saxicola bunting on A549 lung cancer cells proliferation, apoptosis and its effect on Caspase, Survivin expression. Chin J Exp Formulas Chin Med 9: 165-169, 2015 (In Chinese).

35. Ellenbroek SI and Collard JG: Rho GTPases: Functions and association with cancer. Clin Exp Metastasis 24: 657-672, 2007.

36. Vega FM and Ridley AJ: Rho GTPases in cancer cell biology. FEBS Lett 582: 2093-2101, 2008.

37. Razidlo GL, Magnine C, Sletten AC, Hurley RM, Almada LL, Fernandez-Zapico ME, Ji B and McNiven MA: Targeting pancreatic cancer metastasis by inhibition of Vav1, a driver of tumor cell invasion. Cancer Res 75: 2907-2915, 2015.
38. Borkham-Kamphorst E, Alexi P, Tihaa L, Haas U and Weiskirchen R: Platelet-derived growth factor-D modulates extracellular matrix homeostasis and remodeling through TIMP-1 induction and attenuation of MMP-2 and MMP-9 gelatinase activities. Biochem Biophys Res Commun 457: 307-313, 2015.

39. Davis ME, Gumucio JP, Sugg KB, Bedi A and Mendias CL: MMP inhibition as a potential method to augment the healing of skeletal muscle and tendon extracellular matrix. J Appl Physiol (1985) 115: 884-891, 2013.

40. Wang R, Ke ZF, Wang F, Zhang WH, Wang YF, Li SH and Wang LT: GOLPH3 overexpression is closely correlated with poor prognosis in human non-small cell lung cancer and mediates its metastasis through upregulating MMP-2 and MMP-9. Cell Physiol Biochem 35: 969-982, 2015.

41. Xu X, Chen L, Xu B, Xie Q, Sun M, Deng X, Wu C and Jiang J: Increased MT2-MMP expression in gastric cancer patients is associated with poor prognosis. Int $\mathrm{J}$ Clin Exp Pathol 8: 1985-1990, 2015

42. El-Badrawy MK, Yousef AM, Shaalan D and Elsamanoudy AZ: Matrix metalloproteinase-9 expression in lung cancer patients and its relation to serum MMP-9 activity, pathologic type, and prognosis. J Bronchology Interv Pulmonol 21: 327-334, 2014.

43. Buccione R, Caldieri G and Ayala I: Invadopodia: Specialized tumor cell structures for the focal degradation of the extracellular matrix. Cancer Metastasis Rev 28: 137-149, 2009.

44. Yamaguchi H, Lorenz M, Kempiak S, Sarmiento C, Coniglio S, Symons M, Segall J, Eddy R, Miki H, Takenawa T and Condeelis J: Molecular mechanisms of invadopodium formation: The role of the N-WASP-Arp $2 / 3$ complex pathway and cofilin. J Cell Biol 168: 441-452, 2005.

45. Poincloux R, Lizárraga $\mathrm{F}$ and Chavrier P: Matrix invasion by tumour cells: A focus on MT1-MMP trafficking to invadopodia. J Cell Sci 122: 3015-3024, 2009.

46. Sebban S, Farago M, Gashai D, Ilan L, Pikarsky E, Ben-Porath I and Katzav S: Vav1 fine tunes p53 control of apoptosis versus proliferation in breast cancer. PLoS One 8: e54321, 2013.

47. Grassilli S, Brugnoli F, Lattanzio R, Rossi C, Perracchio L, Mottolese M, Marchisio M, Palomba M, Nika E, Natali PG, et al: High nuclear level of Vav1 is a positive prognostic factor in early invasive breast tumors: A role in modulating genes related to the efficiency of metastatic process. Oncotarget 5: 4320-4336, 2014. 